\title{
Conservative mastectomies
}

\begin{abstract}
Conservative Mastectomies provide removal of the entire breast parenchyma, saving the outer covering of the mammary gland with the possibility of performing an immediate reconstruction preserving women body image. With the oxymoron "conservative mastectomies", we indicate Skin-Sparing Mastectomies (SSM), Nipple-Areola ComplexSparing Mastectomies (NSM) and Skin-Reducing Mastectomies (SRM). Eventhough randomized controlled trials comparing conservative mastectomies with traditional mastectomy and breast conserving surgery would be auspicable in order to achieve higher levels of evidence, we could confidently conclude that conservative mastectomies offer the psychological advantages of good cosmesis and maintenance of woman body image without compromising the oncological safety of mastectomy.
\end{abstract}

Volume 2 Issue 3 - 2015

\author{
Rocco Nicola \\ Department of Clinical Medicine and Surgery, University of \\ Naples "Federico II", Italy

\begin{abstract}
Correspondence: Rocco Nicola, Department of Clinical Medicine and Surgery, University of Naples "Federico II",Via Gabriele Jannelli 520, 80 I3। Naples, Italy, Tel 00393393450357 , Fax 0039 08I54693।2, Email nicolarocco@libero.it
\end{abstract}

Received: December 27, 2014 | Published: March 31, 2015

Keywords: skin-sparing mastectomy, nipple-sparing mastectomy, breast cancer

Abbreviations: SSM, skin-sparing mastectomies; NSM, nipple-areola complex-sparing mastectomies; SRM, skin-reducing mastectomies

\section{Conservative mastectomies}

Conservative Mastectomies provide removal of the entire breast parenchyma, saving the outer covering of the mammary gland (subcutaneous fat, skin and nipple (if oncologically safe)) with the possibility of performing an immediate one-stage or twostage implant-based reconstruction or an immediate autologous tissue reconstruction, preserving women body image. Skin-Sparing Mastectomy was first described in 1991 by Toth and Lappert as an effort to maximize skin preservation to improve cosmetic outcome and facilitate reconstruction. ${ }^{1}$ Mastectomy with preservation of the skin and the Nipple-Areola complex was first described even before than SSM: Rice and Stickler in 1951 presented the "adenomammectomy" for benign diseases ${ }^{2}$ and Freeman in 1962 introduced the term "subcutaneous mastectomy". ${ }^{3}$

Other authors in the last 15 years used the terms "total skin-sparing mastectomy", "nipple-sparing mastectomy" or "NAC (nipple-areola complex)-sparing mastectomy". NSM is similar to SSM for the dissection of skin flaps, but also consider the respect of the nippleareola complex. Obviously the additional preservation of the NAC makes the procedure more technically demanding, with the need of complete removal of the retroareolar ducts and preservation of nipple vascularisation.

Some authors recommend the nipple eversion during surgery and the use of sharp dissection instead of electrocautery to limit thermal injury and increase NAC preservation rates. ${ }^{4}$ Some authors attempted to precondition the NAC by dissecting it under local anesthesia from the underlying breast tissues several days before the mastectomy to stimulate blood flow from the peripheral skin. ${ }^{5,6}$ Performing this approach, the authors present the advantage of retroareolar biopsy before mastectomy and the biopsy specimen could be submitted to permanent histological analysis.

Usually, the retroareolar tissues are removed at the time of the conservative mastectomy and the specimen is analyzed by frozen section. Other authors used intraoperative radiotherapy of the NAC when the frozen section of retroareolar tissue is negative, as a riskreducing technique for local recurrence. ${ }^{7}$ An appropriate incision for
NSM should ease both the mastectomy and the reconstruction, preserve the NAC blood flow and guarantee a good cosmetic result. Several incisions have been proposed to achieve these goals: periareolar/ circumareolar (+/- inferolateral or superolateral extension or omega), radial (straight, lateral or vertical), inframammary, inverted-T and transareolar. ${ }^{8-11}$ Trans-areolar and periareolar/circumareolar incisions present the highest risk of NAC necrosis, while lateral radial incision ease the glandular dissection and the access to the axilla for sentinel lymph node biopsy, leaving the NAC untouched. ${ }^{7,12}$

Some surgeons also presented minimally-invasive video-assisted techniques through a mid-axillary skin incision. ${ }^{13,14}$ Survival of the NAC is one of the most important issues when performing a NSM. Complete necrosis of the nipple rates range from 0 to $60 \%{ }^{12,15}$ Factors affecting NAC vascularisation are smoking habit, young age and type of skin incision. ${ }^{16}$ Other common complications are capsular contracture following implant-based reconstruction and skin flap ischaemia. Implant-based reconstruction is extensively used in association with conservative mastectomies, both one-stage (direct-to-implant) and two-stage (expander to implant). Two-stage reconstruction is preferred in case of compromised blood supply reducing the retroareolar pressure, skin tension and flap ischaemia in the immediate postoperative days..$^{17}$ The implant is always positioned under a muscular pocket created by the pectoralis major and the serratus muscles. Human acellular dermal matrices and synthetic meshes could provide lower pole coverage allowing a direct-toimplant reconstruction. ${ }^{18,19}$

\section{Conclusion}

Conservative mastectomies provide a better quality of life for women with breast cancer. The preservation of the nippleareola complex in particular offers the possibility of preserving the woman body image. Even if the studies indagating conservative mastectomies are low-evidenced, the low rates of local recurrence reported in several large retrospective series and prospective cohorts with 5-year survival rates of more than $95 \%$ reassure both patients and surgeons. Eventhough randomized controlled trials comparing conservative mastectomies with traditional mastectomy and breast conserving surgery would be auspicable in order to achieve higher levels of evidence to answer to many open questions (the minimum distance between tumor and nipple, maximum tumor size, best skin incision, type of reconstruction), we could confidently conclude 
that conservative mastectomies offer the psychological advantages of good cosmesis and maintenance of woman body image without compromising the oncological safety of mastectomy.

\section{Acknowledgments}

None.

\section{Conflicts of interest}

Author declares that there is no conflict of interest.

\section{References}

1. Toth BA, Lappert P. Modified skin incisions for mastectomy: the need for plastic surgical input in preoperative planning. Plast Reconstr Surg. 1991;87(6):1048-1053.

2. Rice CO, Strickler JH. Adeno-mammectomy for benign breast lesions. Surg Gynecol Obstet. 1951;93(6):759-762.

3. Freeman BS. Subcutaneous mastectomy for benign breast lesions with immediate or delayed prosthetic replacement. Plast Reconstr Surg Transplant Bull. 1962;30:676-682.

4. Chung AP, Sacchini V. Nipple-sparing mastectomy: where are we now? Surg Oncol. 2008;17(4):261-266.

5. Palmieri B, Baitchev G, Grappolini S, et al. Delayed nipple-sparing modified subcutaneous mastectomy: Rationale and technique. Breast $J$. 2005;11(3):173-178.

6. Jensen JA, Lin JH, Kapoor N, et al. Surgical delay of the nipple-areolar complex: A powerful technique to maximize nipple viability following nipple-sparing mastectomy. Ann Surg Oncol. 2012;19(10):3171-3176.

7. Petit JY, Veronesi U, Orecchia R, et al. Nipple sparing mastectomy with nipple areola intraoperative radiotherapy: One thousand and one cases of a five years experience at the European institute of oncology of Milan (EIO). Breast Cancer Res Treat. 2009;117(2):333-338.

8. Garcia-Etienne CA, Cody lii HS, Disa JJ, et al. Nipple-sparing mastectomy: Initial experience at the Memorial Sloan-Kettering Cancer Center and a comprehensive review of literature. Breast $J$. 2009;15(4):440-449.
9. Colwell AS, Gadd M, Smith BL, et al. An inferolateral approach to nipple-sparing mastectomy: Optimizing mastectomy and reconstruction. Ann Plast Surg. 2010;65(2):140-143.

10. Rawlani V, Fiuk J, Johnson SA, et al. The effect of incision choice on outcomes of nipple-sparing mastectomy reconstruction. Can J Plast Surg. 2011;19(4):129-133.

11. Moyer HR, Ghazi B, Daniel JR, et al. Nipple-sparing mastectomy: Technical aspects and aesthetic outcomes. Ann Plast Surg. 2012;68(5):446-450.

12. Garwood ER, Moore D, Ewing C, et al. Total skin-sparing mastectomy: Complications and local recurrence rates in 2 cohorts of patients. Ann Surg. 2009;249(1):26-32.

13. Sakamoto N, Fukuma E, Higa K, et al. Early results of an endoscopic nipple-sparing mastectomy for breast cancer. Ann Surg Oncol. 2009;16(12):3406-3413

14. Nakajima H, Fujiwara I, Mizuta N, et al. Clinical outcomes of videoassisted skin-sparing partial mastectomy for breast cancer and immediate reconstruction with latissimus dorsi muscle flap as breast-conserving therapy. World J Surg. 2010;34(9):2197-2203.

15. Regolo L, Ballardini B, Gallarotti E, et al. Nipple sparing mastectomy: An innovative skin incision for an alternative approach. Breast. 2008;17(1):8-11.

16. Algaithy ZK, Petit JY, Lohsiriwat V, et al. Nipple sparing mastectomy: Can we predict the factors predisposing to necrosis? Eur J Surg Oncol. 2012;38(2):125-129.

17. Garwood ER, Moore D, Ewing C, et al. Total skin-sparing mastectomy: Complications and local recurrence rates in 2 cohorts of patients. Ann Surg. 2009;249(1):26-32.

18. Salzberg CA, Ashikari AY, Koch RM, et al. An 8-year experience of direct-to-implant immediate breast reconstruction using human acellular dermal matrix (AlloDerm). Plast Reconstr Surg. 2011;127(2):514-524.

19. Colwell AS, Damjanovic B, Zahedi B, et al. Retrospective review of 331 consecutive immediate single-stage implant reconstructions with acellular dermal matrix: indications, complications, trends, and costs. Plast Reconstr Surg. 2011;128(6):1170-1178. 